\title{
Erase-Maintain-Establish: Natural Reprogramming of the Mammalian Epigenome
}

\author{
Milena Leseva, ${ }^{1}$ Barbara B. Knowles, ${ }^{2}$ Daniel M. Messerschmidt, ${ }^{1}$ and Davor Solter ${ }^{3}$ \\ ${ }^{1}$ Department for Developmental Epigenetics and Disease, Institute of Molecular and Cell Biology, \\ A*STAR, 138673 Singapore \\ ${ }^{2}$ Emerita, The Jackson Laboratory, Bar Harbor, Maine 04609 \\ ${ }^{3}$ Emeritus Member and Director, Max-Planck Institute of Immunobiology and Epigenetics, \\ 79180 Freiburg, Germany \\ Correspondence: Danielm@imcb.a-star.edu.sg;davorsolter@mac.com
}

\begin{abstract}
The genetic information is largely identical across most cell types in a given organism but the epigenome, which controls expression of the genome, is cell type- and context-dependent. Although most mature mammalian cells appear to have a stable, heritable epigenome, a dynamic intricate process reshapes it as these cells transition from soma to germline and back again. During normal embryogenesis, primordial germ cells, of somatic origin, are set aside to become gametes. In doing so their genome is reprogrammed - that is, the epigenome of specific regions is replaced in a sex-specific fashion as they terminally differentiate into oocytes or spermatocytes in the gonads. Upon union of these gametes, reprogramming of the new organism's epigenome is initiated, which eventually leads, through pluripotent cells, to the cell lineages required for proper embryonic development to a sexually mature adult. This never-ending cycle of birth and rebirth is accomplished through methylation and demethylation of specific genomic sites within the gametes and pluripotent cells of an organism. This enigmatic process of natural epigenomic reprogramming is now being dissected in vivo, focusing on specific genomic regions - that is, imprinted genes and retrotransposons, where TRIM28 molecular complexes appear to guide the transition from gamete to embryo.
\end{abstract}

Mammalian reproduction requires union of two highly specialized cells, the egg and sperm, at fertilization, an event that marks the beginning of new life. Epigenetic marks of this newly formed genome are immediately required to establish the cell type-specific gene expression programs required for embryonic growth and development. DNA methylation is an epigenetic modification that leads to repression of specific gene expression, Xchromosome inactivation, and silencing of mobile DNA elements (for review, see Messerschmidt et al. 2014) and affects alternative splicing (Yearim et al. 2015). Establishment and maintenance of stable methylation patterns are thus crucial to execution of a normal developmental program (Okano et al. 1999). The DNA methylome should be, and is, extremely plastic during very early embryogenesis. Its dynamic control is initiated at fertilization during the switch from germ cell to embryospecific methylation and a reciprocal change manifests during germ cell specification with the switch from a somatic to a germline epigenomic signature (Fig. 1).

Fertilization triggers extensive reprogramming whereby the global DNA hypermethylation of the germ cellspecific epigenomes become, on the whole, demethylated. The paternal genome in the pronucleus of the zygote is rapidly demethylated and reorganized. The methylation of the maternal genome is gradually depleted in a replication-dependent manner over consecutive mitotic divisions (Santos and Dean 2004). Although the precise mechanics of the active process are not completely un- derstood, TET3-mediated oxidation of 5-methylcytosine (5mC) (Gu et al. 2011; Iqbal et al. 2011; Wossidlo et al. 2011) and restoration of unmethylated cytosines by components of the base excision repair pathway (Hajkova et al. 2010) are involved. These changes to the embryonic genome lead to an open chromatin state, essential for the pluripotency of some cells in the mouse blastocyst's inner cell mass (ICM). Reacquisition of de novo promoter methylation occurs between the time of establishment of the ICM of the blastocyst and the development of the postimplantation epiblast when the cells of the embryo differentiate into the somatic lineages (Borgel et al. 2010).

Resetting the epigenome is also mandatory during primordial germ cell (PGC) development when the methylation marks of the parental epigenome are erased and new gender-specific imprinting patterns are established (Seisenberger et al. 2012). PGCs are specified at E6.5 from a small group of BLIMP1-positive cells located in the somatic proximal postimplantation epiblast (for review, see Magnúsdóttir and Surani 2014). In mouse PGCs 5mC levels gradually decline in a partially TET $1 / 2$-dependent manner, as the cells migrate through the hindgut endoderm (E9.5), reach the gonadal anlagen (E11.5), and undergo sexual determination (E13.5) (Fig. 1).

Given the size and complexity of the mammalian genome, it is fascinating that demethylation and remethylation events are intricately controlled both temporally and in a genome context-specific manner. How are cer- 


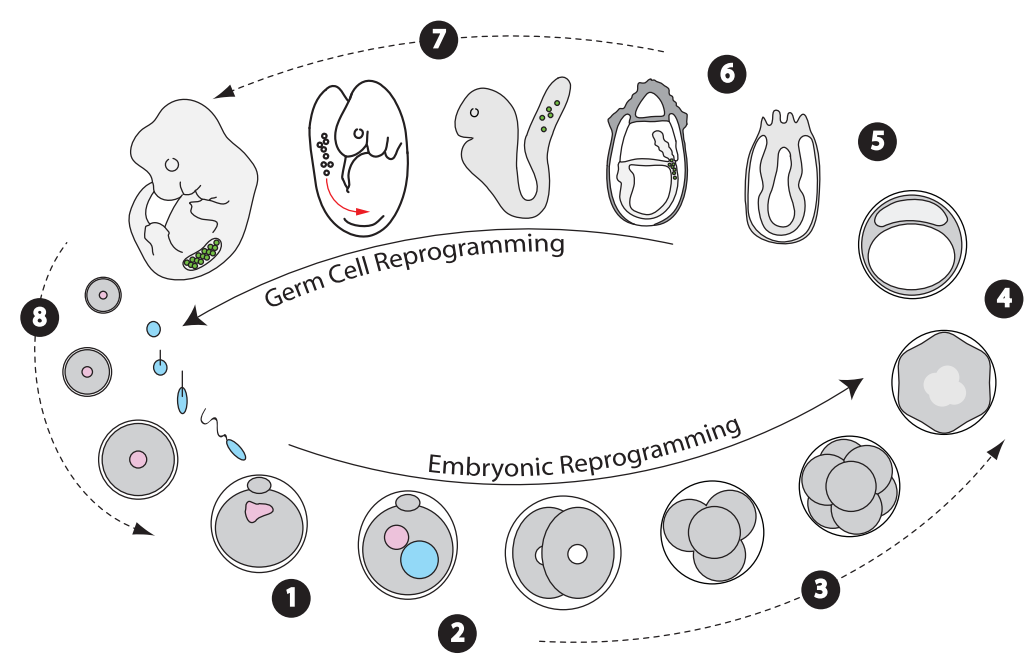

Figure 1. Epigenetic reprogramming during the mammalian reproductive cycle. (1) Both male and female germ cells are differentiated cell types and have highly specialized epigenomes. Fertilization of the oocyte by sperm initiates embryonic development. (2) The paternal genome (blue) is rapidly demethylated at early pronuclear stages. (3) The maternal genome (pink) is passively demethylated in a replication-dependent manner. (4) Erasure of germ cell-specific DNA methylation patterns allows the establishment of the pluripotent inner cell mass of the blastocyst. (5) Pluripotent cells begin the acquisition of DNA methylation marks as they begin to differentiate into somatic lineages. (6) PGCs are specified in the proximal postimplantation epiblast. They carry somatic epigenetic features, such as genomic imprints, inactive X-chromosomes, and silenced germ cell/pluripotency genes. (7) These features and potential epimutations are erased during primordial germ cell reprogramming. (8) Male- and female-specific germ cell differentiation includes establishment of paternal and maternal imprints.

tain loci identified to escape the loss of DNA methylation in an environment that favors genome-wide demethylation events? Recent studies of the molecular interactions at specific sites in imprinted genes and in endogenous retroelements (EREs) have afforded a glimpse of this complex process. Because methylation protection of specific DNA regions initiates immediately after fertilization, and during a time of complete transcriptional silence, the molecular agents, either RNA and/or protein, must be in the oocyte - that is, maternally inherited. The role of one such maternal factor, TRIM28, will be used to illustrate the complexity of this process in the mouse.

\section{TRIM28-A MULTIFACETED WORKER IN THE CHROMATIN FIELD}

Tripartite motif containing 28/KRAB-domain-associated protein $1 /$ transcription intermediary factor- $1 \beta$ (TRIM28/KAP1/TIF1 $\beta$ ) is a multifunctional protein implicated in processes as diverse as embryonic development, maintenance of pluripotency, imprinting, endogenous and exogenous retroviral silencing, and double-strand break DNA damage response, to name a few. The structure of TRIM28, with its amino-terminal RING, B-box, and coiled-coil (RBCC) domain, central HP1binding domain, and carboxy-terminal PHD-bromodomains, provides it with the means to interact with multiple transcription factors (TFs) and a variety of chromatin remodelers and epigenetic modifiers (Iyengar and Farnham 2011; Cheng 2014).

TRIM28 itself does not bind to DNA directly but rather relies on DNA-binding TF-mediated recruitment. These are largely members of the Krüppel-associated box
(KRAB) domain zinc-finger proteins (ZFPs), a family of TFs containing more than 200 genes in mice and humans that encode distinct proteins with highly variable DNA-binding domains. KRAB-ZFPs may have evolved from $\operatorname{Prdm} 9$ (Meisetz) (Birtle and Ponting 2006) and expanded rapidly by duplication events during evolution. Loss of the original SET domain, accumulation of sequence changes to the ancestral KRAB domain, and appearance of corepressors are responsible for establishing the KRAB-ZFPs as transcriptional repressors. One explanation for the huge expansion and diversification of these TFs lies in their presumed coevolution with EREs to prevent their transcriptional reactivation (Thomas and Schneider 2011).

KRAB-ZFPs contain tandem arrays of $\mathrm{C} 2 \mathrm{H} 2$ zinc fingers, each engaging three consecutive nucleotides on one DNA strand and one nucleotide on the opposite strand. The combination of multiple ZNFs within one protein allows KRAB-ZFPs to bind with high specificity and to recognize long stretches of DNA. The amino-terminally encoded KRAB domain is highly conserved throughout the KRAB-ZFP family and mediates interaction with TRIM28.

Numerous other TFs have been reported to interact with and potentially attract TRIM28 to their DNA-binding sites (Fig. 2; Satou 2001; Li et al. 2003; Satou et al. 2004; Wang et al. 2005, 2007; Jin et al. 2007; Tsuruma et al. 2007; Kamitani et al. 2008, 2011; Peng et al. 2009; Seki et al. 2010; Liang et al. 2011; Maruyama et al. 2011; Huang et al. 2013). For most of these, the KRAB-ZFPs included, TRIM28 functions as a co-repressor down-regulating gene transcription by its heterochromatin-inducing activity at its target sites (Iyengar and Farnham 2011; Cheng 2014). 
A The TRIM28-complex
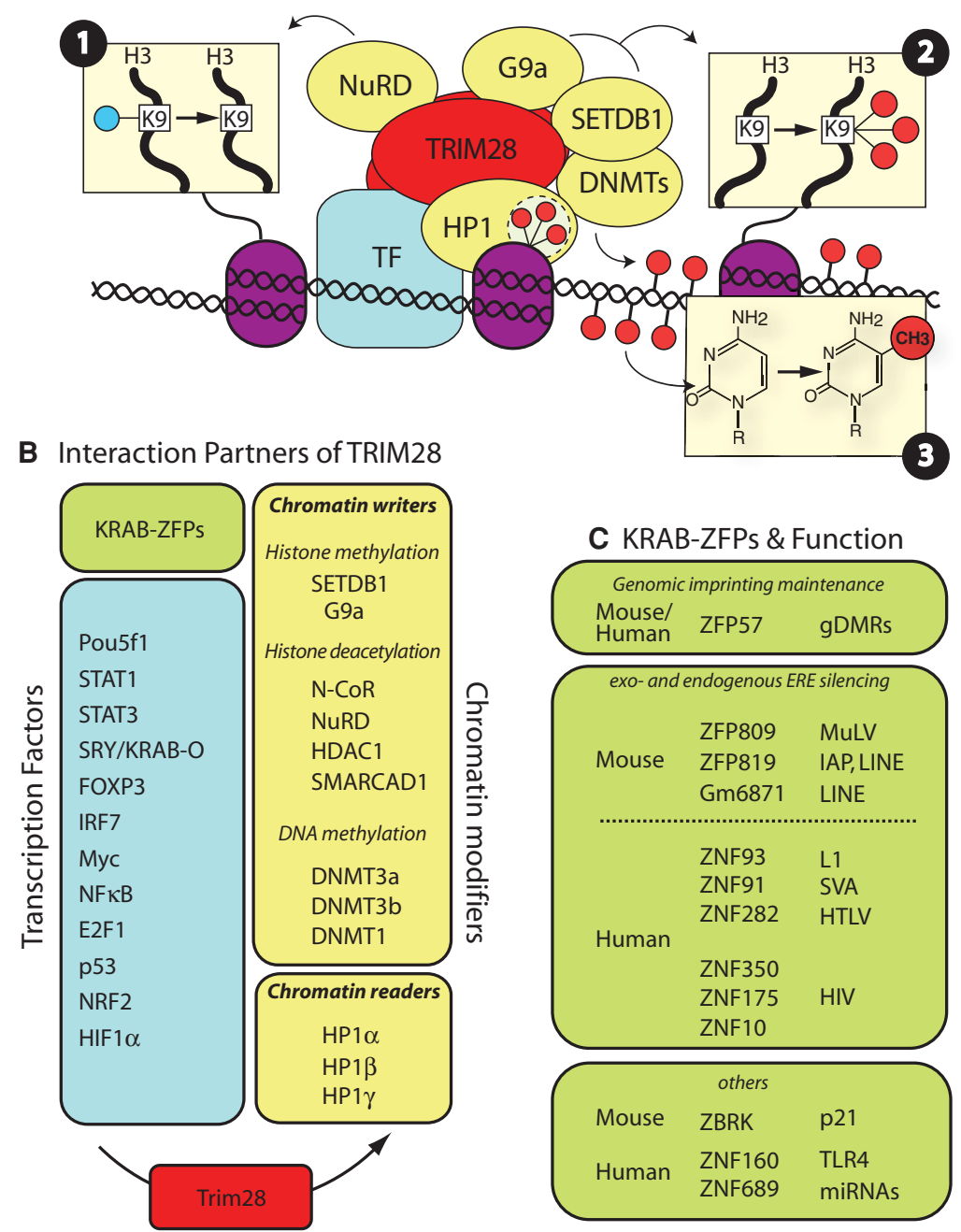

Figure 2. The TRIM28 complex and interactome. (A) TRIM28 acts as a central scaffolding protein for a multifunctional, large protein complex. It is guided to DNA by interacting transcription factors and attracts in turn: (1) The NuRD histone deacetylation complex (deacetylates H3K9Ac); (2) SETDB1 and G9a histone methyltransfereases (trimethylate H3K9me3); (3) DNA methyltransferases (DNMTs) (methylate cytosines). Heterochromatin protein 1 (HP1) recognizes H3K9me3 chromatin and further physically interacts with TRIM28. $(B)$ TRIM28 interaction partners: KRAB-ZFPs and other TFs can target TRIM28 to DNA (left) (Satou 2001; Li et al. 2003; Satou et al. 2004; Wang et al. 2005, 2007; Jin et al. 2007; Tsuruma et al. 2007; Kamitani et al. 2008, 2011; Peng et al. 2009; Seki et al. 2010; Liang et al. 2011; Maruyama et al. 2011; Huang et al. 2013). TRIM28 attracts chromatin writers and readers (right) (Nielsen et al. 1999; Ryan et al. 1999; Schultz et al. 2001, 2002; Quenneville et al. 2011; Zuo et al. 2012). (C) Few KRAB-ZFP proteins have been studied in detail. ZFP57 plays a conserved role in imprinting maintenance in humans and mice. Diverse ZFPs/ZFNs (mouse/human) are involved in retrovirus silencing and other physiological functions (Okumura et al. 1997; Zheng et al. 2000; Li et al. 2008; Takahashi et al. 2009; Wolf and Goff 2009; Quenneville et al. 2011; Nishitsuji et al. 2012, 2015; Tan et al. 2013; Castro-Diaz et al. 2014; Jacobs et al. 2014; Wolf et al. 2015b).

TRIM28 acts as a scaffolding protein associating with the H3K9me3-writer SETDB1/ESET, the H3K9me3reader $\mathrm{HP} 1$, and the nucleosome remodeling and histone deacetylation complex NuRD (Schultz et al. 2002, 2001). This multisubunit, heterochromatin-inducing molecular complex also serves as a platform for recruiting DNA methyltransferases, which can then induce and maintain DNA methylation in proximity to their target sites (Fig. 2; Quenneville et al. 2011; Zuo et al. 2012).

From a developmental biologist's point of view, it was known for some time that Trim 28 was highly expressed in the preimplantation embryo and that its zygotic knockout is embryonic lethal in early postimplantation stages (Cammas et al. 2000). Trim28 was also identified in independent screens for factors required for pluripotency and self-renewal of embryonic stem cells (ESCs) (Fazzio et al. 2008; Hu et al. 2009). However, the precise role of Trim 28 in mammalian cells remained unclear, although it was found to relocalize to centromeric heterochromatin upon cell differentiation (Cammas et al. 2002).

Additional insights to TRIM28 function in vivo were gained from studies in preimplantation embryos 
(Messerschmidt 2012; Messerschmidt et al. 2012). Deletion of maternal Trim 28 alone causes embryonic lethality, despite its reexpression from the paternal allele following embryonic genome activation at the two-cell stage. Intriguingly, the maternal-null embryos show highly variable phenotypes and die at various times throughout gestation, albeit at a much later time than when the molecular deficiency of TRIM28 first occurs. The pleiotropic defects displayed by these embryos are indicative of accumulated, random combinations of epimutations incompatible with life (Messerschmidt et al. 2012; Lorthongpanich et al. 2013).

We now know that TRIM28 is essential for proper and successful epigenetic reprogramming through at least two fundamental functions - that is, maintaining imprinting and silencing retrotransposons.

\section{THE TRIM28-COMPLEX FUNCTION IN GENOMIC IMPRINTING}

Genomic imprinting, or the establishment and maintenance of monoallelic expression of particular genes in a parent-of-origin-specific manner, is at the heart of the developmental failure observed in genetically bimaternal (gynogenote) and bipaternal (androgenote) embryos. The observation that the incomplete development of embryos derived from gynogenotes is largely embryo-like, whereas that of androgenotes is mostly of extraembryonic-like tissues, showed that the maternal and paternal genomes are functionally nonequivalent (McGrath and Solter 1984; Surani et al. 1984). Imprinting implies that the maternal and paternal genomes are differentially marked at specific genetic loci but does not involve changes in the DNA sequence. These epigenetic marks regulate gene expression, are mitotically heritable, and are set during female and male gametogenesis, respectively. Imprinted genes are often clustered in specific sites of the genome and within these clusters they can be coordinately regulated by differentially methylated regions at the so-called imprinting control regions (ICRs). Methylation at ICRs ultimately controls gene expression in cis by multiple mechanisms. Many imprinting clusters express noncoding RNAs (ncRNAs) that can further regulate genes within the cluster in trans. Collectively, epigenetic modification ensures that maternally imprinted genes are expressed from the maternally transmitted allele and silenced on the paternal allele, and vice versa (Hanna and Kelsey 2014; Peters 2014).

Parent-specific DNA methylation patterns at the ICRs are instituted during gametogenesis, part of a process requiring erasure of the inherited parental marks, so that imprints can be established sex-specifically. These parental imprints are protected and preserved postfertilization and stabilized throughout embryonic and adult life, as proper levels of the product of imprinted genes are essential to embryonic development, or are involved in adult cell and tissue homeostasis. For this reason, specialized mechanisms must be put in place to protect such sites from erasure during the wave of demethylation in the early embryo. Genomic imprints are therefore paradigmatic of the subtle epigenetic fine-tuning required during genomic reprogramming. Although the genomic imprinting cycle of "erasure-establishment-maintenance and erasure again" has been postulated and shown for some time, the molecular mechanisms behind imprint maintenance involving the TRIM28 complex were only recently unraveled.

Demethylation in the preimplantation embryos is achieved by a combination of active and passive erasure of the methylation from $5 \mathrm{mC}$ (for review, see Messerschmidt et al. 2014). To allow for efficient methylation removal, the maintenance DNA methyltransferase-1 (DNMT1) is largely excluded from the nuclei of the cleavage-stage embryos (Howell et al. 2001; Ratnam et al. 2002; Branco et al. 2008; Hirasawa et al. 2008). However, this compartmentalization and nuclear exclusion cannot be complete, as genetic deletion of both maternal and zygotic Dnmt1 results in imprinting defects, the result of complete ICR demethylation (Hirasawa et al. 2008). DNMT1 is canonically targeted to the replication fork in mitotic cells by its cofactor NP95. Because the drastically reduced DNMT1 levels and the global DNA methylation maintenance function of this complex make it unlikely to maintain imprints in embryos, a noncanonical targeting mechanism of DNMT1 had been proposed.

Insights into how DNMT1 might be targeted specifically to ICRs came from studies in vivo and in vitro. We were able to show that loss of maternal Trim28 alone can result in dramatic misexpression of imprinted genes in midgestation embryos (Messerschmidt 2012; Messerschmidt et al. 2012, 2014; Lorthongpanich et al. 2013). This observed deregulation was observed across multiple imprinting clusters with the deregulation following a pattern predicated on a loss-of-ICR-methylation scenario. Indeed, partial, severe ICR demethylation, predominantly at the paternally imprinted H19/IGF2 locus, was found in these embryos. All tested imprinted loci, however, displayed variable degrees of methylation loss, arguing for (1) a global mechanism and (2) a partial rescue of the defect by paternal Trim 28 expression (Messerschmidt et al. 2012; Lorthongpanich et al. 2013). Indeed, single-cell analysis of DNA methylation in eight-cellstage embryos revealed that not all blastomeres are affected equally; hence, the pleiotropic defects observed are likely a consequence of epigenetic mosaicism in the mutant embryos. Interestingly, maternal/zygotic-null Trim 28 embryos develop to apparently normal blastocysts and implant (DM Messerschmidt, unpubl.); thus, the complete knockout does not show a phenotype during preimplantation embryogenesis. However, it remains to be seen whether loss of both maternal and paternal Trim 28 will result in complete eradication of ICR methylation in preimplantation embryos.

TRIM28 is physically bound to known ICRs in midgestation embryos, arguing for a direct recognition and maintenance mechanism (Messerschmidt et al. 2012). ICRs in these embryos are co-occupied by ZFP57 and as a consequence of the binding of the TRIM 28 complex, histones were H3K9me3 modified (Messerschmidt et al. 
2012). ZFP57 is a TRIM28-interacting KRAB-ZFP and both maternal and zygotic Zfp57 are necessary for the proper maintenance of parental imprints in blastocysts (Li et al. 2008). Investigations in ESCs showed ZFP57 recognizes a $\mathrm{CpG}$-containing consensus TGCCGC sequence, highly conserved at ICRs (Quenneville et al. 2011). However, TRIM28 binding to hypomethylated sites was lost in embryos (Messerschmidt et al. 2012) leading us to suggest that ZFP57 recognizes the methylated cytosine. Indeed, ZFP57 shows much higher affinity to its methylated target sequence in vitro (Quenneville et al. 2011; Liu et al. 2012). Thus, sequence-specific and methylation-dependent binding to ICRs offers an elegant solution to the convoluted undertaking of (1) recognizing specialized regions within the genome and (2) maintaining differential DNA methylation at a given locus. It also explains the lack of paternal rescue in the maternal Trim28-null embryo because preexisting DNA-methylated sites, inherited from the gametes, are fundamental to the ZFP57-mediated TRIM28-complex binding. If a particular $\mathrm{CpG}$ is demethylated under maternal-null circumstances, reexpressed paternal TRIM28 cannot be targeted to it and cannot restore DNA methylation. Similarly, reexpression of ZFP57 in Zfp57-deleted ES cells cannot restore methylation to sites that have lost it (Zuo et al. 2012). Finally, this mode of interaction offers a plausible model for the noncanonical targeting of the dramatically reduced levels of DNMT1 to ICRs in preimplantation embryos; both maintenance DNAmethyltransferase and the de novo DNA-methyltransferases (DNMT3A/B) are bona fide interaction partners of TRIM28 (Quenneville et al. 2011; Zuo et al. 2012).

The highly specialized role and mode of chromatin interaction of ZFP57 with specific genomic sequences, be they methylated or not, is an exquisite example of the functional diversity acquired by the KRAB-ZFPs. Further, the multiple interactions made possible through the TRIM28 scaffolding complex not only clarify the specificity of epigenetic reprogramming but also accentuate the importance of the balance between erasure of most parental epigenetic features versus the careful maintenance of a few stable epigenetic sites.

\section{THE TRIM28 COMPLEX IN RETROTRANSPOSON REGULATION}

Mammalian cells face a formidable challenge in dealing with potentially damaging endogenous retroviruses (ERVs) and retrotransposons, collectively termed endogenous retroviral elements (EREs). These elements make up $\sim 40 \%$ of the mammalian genome, highlighting the magnitude of this task (Lander et al. 2001; Mouse Genome Sequencing Consortium et al. 2002).

Aberrant activation of EREs can impact the host on two major levels. For one, certain retrotransposons remain capable of active retrotransposition that can lead to random insertional mutagenesis following replicative transposition into the host's genome. This must be prevented at all costs, particularly in the germline. Most EREs, however, have lost their ability to replicate but still their remnants are important targets of the host's silencing machinery. Loss of silencing at such sites can result in drastic, localized chromatin changes and impact on certain cellular genes whose expression may be under the influence of neighboring, ERE-derived promoters/enhancers. In certain contexts, ERE control over gene regulation and mobility is of beneficial effect to the host. A case in point is the developmentally regulated expression of nonconventional chimeric transcripts driven by transposon-derived $5^{\prime}$ sequences that can encode new proteins with potentially novel functions (Peaston et al. 2004). Temporary loss of a silencing mechanism can also explain the stage-specific expression of different long terminal repeat (LTR) retrotransposons during the oocyte-to-embryo transition (Peaston et al. 2004). As it now stands, most EREs are continuously repressed and the first line of defense against their expression is DNA methylation-based silencing, substantially contributing to the overall hypermethylated state of the mammalian genome.

One insight into the molecular mechanism controlling retrotransposon silencing during embryonic development came from the discovery that Dnmt1-deficient embryos reactivate all major classes of the intracisternal A-type particles (IAPs) (Walsh et al. 1998). Later, DNMT3L was shown to protect against spurious transcriptional reactivation of long interspersed nuclear elements 1 (L1NE1) and I $\Delta 1$ IAP retrotransposons in male germ cells (Bourc'his and Bestor 2004). Extensive research has shown that during mammalian reproduction, when DNA methylation patterns are globally modified and removed, other mechanisms serve as a barrier to ERE activation. The small RNAs (piRNAs) seem to predominant in the germline but in the embryo piRNAs play a minor role to that of the KRAB-ZFP TFs, which mediate formation of heterochromatin.

One transacting repressor complex specific to pluripotent cells, and present in embryos, was shown to be important for ERV silencing. Initially termed binding factor A, this 1.3-MDa multisubunit complex contains TRIM28 as a repressor subunit (Reik 2007) and the KRABZFP809 that serves as its sequence-specific DNA-binding partner (Wolf and Goff 2009). TRIM28 links the DNA methylation and KRAB-ZFP repressive machineries as shown by tethering a doxycycline-controllable KRAB domain to a lentiviral construct in vivo (Wiznerowicz et al. 2007). Here, a green fluorescent protein (GFP) reporter gene was found to be expressed only if recruitment of the repressive KRAB-ZFP was prevented by adding doxycycline in a narrow time window right after fertilization (between E0.5 and E3.5). Conversely, GFP silencing was permanently established if the KRABcontaining fusion protein bound its target sequence very early in embryogenesis.

ERVs are classified based on their sequence similarities. Class I and particularly class II ERVs such as IAPs and MusD are drastically deregulated in mouse ESCs lacking TRIM28. Also, treatment of Trim 28 knockout- 
derived ESCs with 5-azacytidine (a DNMT inhibitor) has a synergistic effect on ERV activation. However, concurrent reactivation is accompanied by depletion of the H3K9me3 histone modification of the IAP and MusD sequence. DNA methylation-independent silencing in ESC has also been described, which requires TRIM28 and SETDB1 but does not rely on de novo or maintenance methylation because Dnmt1/3a/3b triple-knockout ESCs do not display the massive derepression of murine leukemia virus (MLV), IAP, and MusD observed in Setdb1or Trim28-deficient cells (Matsui et al. 2010; Rowe et al. 2010).

It appears that certain redundant mechanisms function to ensure efficient ERV silencing; the preferred mechanism depends on the class and evolutionary history of the particular element (ancient vs. young). It has been suggested that the repressive KRAB-ZFP machinery likely coevolved together with the ERVs as a host mechanism to restrict their horizontal and vertical transmission (Wolf et al. 2015a,b). Surprisingly, only a limited number of KRAB-ZFPs have been shown to regulate specific ERV classes in mice. Such examples include the regulation of MLV by ZFP809 described earlier, of IAPs and LINE1 by ZFP819, and of LINE1 by Gm6871 (Fig. 2). It remains to be seen whether and which KRAB-ZFPs are still actively involved exclusively in retrotransposon silencing and whether many have evolved to undertake "endogenous" host gene regulatory functions, such as ZFP57.

ERV repression by the TRIM28 complex has been scantily studied in vivo. Class II ERVs, particularly IAP elements, are known to be massively activated in zygotic Trim 28 knockout blastocysts and periimplantation embryos (Rowe et al. 2010). During oocyte growth, these elements are generally repressed (Peaston et al. 2004) but ZP3-cre-mediated removal of maternal Trim 28 in the growing oocyte does not result in IAP or MusD derepression nor in the ectopic activation of any other retroviral element tested here (Fig. 3). Thus, Trim 28 independent mechanisms, in collaboration with DNA methylation and possibly piRNAs, may act to silence ERVs in the mouse egg.

As early as the two-cell stage, when the embryonic genome is activated, a veritable explosion of ERV transcription takes place. Predominantly class III mouse transcript (MT) and ERV-like elements (ERVL) and class II elements (IAPs) are transcribed (Kigami et al. 2003; Peaston et al. 2004). This massive activation of ERVs gives the two-cell-stage mouse embryo a characteristic transcriptome that is recapitulated in a small subfraction (1\%) of ESCs (Kigami et al. 2003; Macfarlan et al. 2012). It is unclear whether this wave of transcriptional activation is required for proper development or is only a byproduct of epigenetic reprogramming in the embryo.

Mouse (Mu) ERVL transcription is regulated by chromatin modifications, particularly $\mathrm{H} 3 \mathrm{~K} 4 \mathrm{me} 3$. Removal of LSD1/KDM1, an $\mathrm{H} 3 \mathrm{~K} 4 \mathrm{me} 3$ demethylase, results in MuERVL activation and embryonic arrest at gastrulation (Macfarlan et al. 2012). We find loss of maternal Trim 28 does not impact MuERVL expression or that of any other class III or class I ERV tested. Also LINE and short interspersed nuclear element (SINE) expression remained unchanged (Fig. 3). Remarkably, despite the massive endogenous activation of class II element observed at the two-cell stage, loss of maternal Trim 28 causes a hyperactivation of IAPs and MusD (Fig. 3). The dynamics of this regulation and to what extent this overexpression, with all its repercussions, contributes to the maternal-deletion phenotype of Trim 28 are unclear and warrant further investigation.
A MII Oocyte
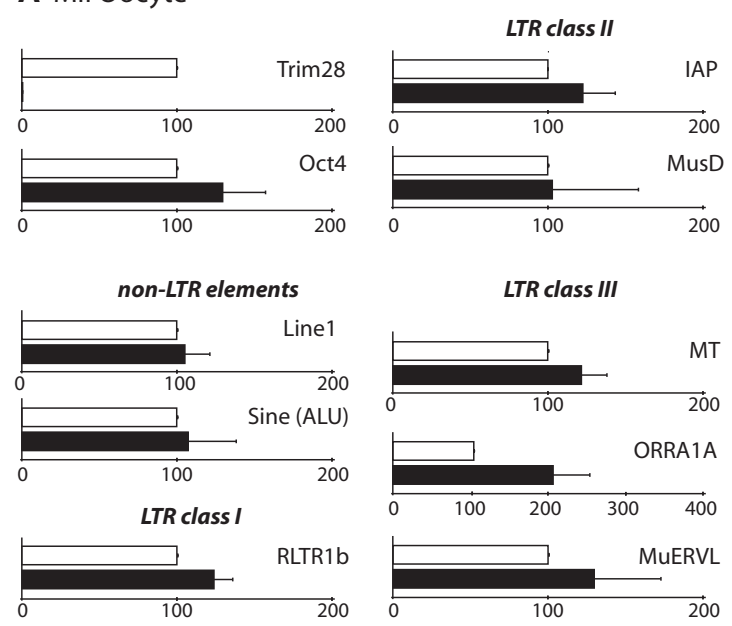

\section{B Two-Cell Stage}
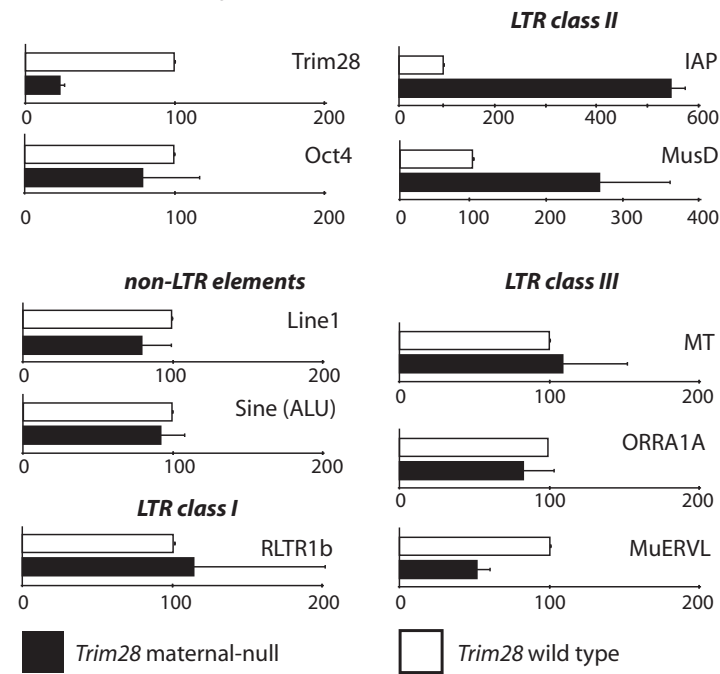

Figure 3. ERV expression in maternal-null Trim 28 and wild-type oocytes and embryos. Long terminal repeat (LTR) and non-LTR retrotransposon expression was tested in $(A)$ MII oocytes and $(B)$ two-cell-stage embryos in the presence and absence of maternal $\operatorname{Trim} 28$ (white and black bars, respectively). Although oocytes show no changes in ERV expression, two-cell-stage maternal-null Trim 28 embryos show elevated expression of the LTR class II elements, IAP and MusD. 


\section{CONCLUSION}

Establishment of a unique epigenome is the basis for correct functioning of each cell in a multicellular organism. Mechanistically we can envision the existence of two types of epigenome. The dynamic or transitory epigenome is unique to each cell and tissue type, and it is driven by classical TFs. It is malleable and reprogrammable as showed by the phenomena of cloning, transdifferentiation, and induced pluripotent stem (iPS) cell derivation. In the stable epigenome, as represented by imprinted genes and retroelements, silencing is based predominantly on stable genomic modifications, which are mitotically inherited and change only at the specific stages of the life cycle of the organism. Establishment and control of the stable epigenome has likely evolved through an evolutionary process we are just beginning to decipher. Considering the importance of a stable epigenome to normal development, significant efforts should be undertaken to understand its establishment and maintenance.

\section{ACKNOWLEDGMENTS}

We thank the members of the Developmental Epigenetics and Disease Laboratory and Heike Wollmann for their comments and input to this work; Mimi DeVries, The Jackson Laboratory, USA and Anne Peaston, University of Adelaide, Roseworthy, Australia for their early contributions. M.L. and D.M.M. are supported by the National Research Foundation (Singapore), A*STAR's Bio-Medical Research Council, and A*STAR's Institute of Molecular and Cell Biology, Singapore. B.B.K., D.S., and D.M.M. were previously supported by A*STAR's Institute of Medical Biology, Singapore.

\section{REFERENCES}

Birtle Z, Ponting CP. 2006. Meisetz and the birth of the KRAB motif. Bioinformatics 22: 2841-2845.

Borgel J, Guibert S, Li Y, Chiba H, Schübeler D, Sasaki H, Forné T, Weber M. 2010. Targets and dynamics of promoter DNA methylation during early mouse development. Nat Genet 42: 1093-1100.

Bourc'his D, Bestor TH. 2004. Meiotic catastrophe and retrotransposon reactivation in male germ cells lacking Dnmt3L. Nature 431: 96-99.

Branco MR, Oda M, Reik W. 2008. Safeguarding parental identity: Dnmt1 maintains imprints during epigenetic reprogramming in early embryogenesis. Genes Dev 22: $1567-$ 1571.

Cammas F, Mark M, Dollé P, Dierich A, Chambon P, Losson R. 2000. Mice lacking the transcriptional corepressor TIF $1 \beta$ are defective in early postimplantation development. Development 127: 2955-2963.

Cammas F, Oulad-Abdelghani M, Vonesch J-L, Huss-Garcia Y, Chambon P, Losson R. 2002. Cell differentiation induces TIF1 $\beta$ association with centromeric heterochromatin via an HP1 interaction. J Cell Sci 115: 3439-3448.

Castro-Diaz N, Ecco G, Coluccio A, Kapopoulou A, Yazdanpanah B, Friedli M, Duc J, Jang SM, Turelli P, Trono D. 2014. Evolutionally dynamic L1 regulation in embryonic stem cells. Genes Dev 28: 1397-1409.

Cheng C-T. 2014. KAPtain in charge of multiple missions: Emerging roles of KAP1. World J Biol Chem 5: 308-320.
Fazzio TG, Huff JT, Panning B. 2008. An RNAi screen of chromatin proteins identifies Tip60-p400 as a regulator of embryonic stem cell identity. Cell 134: 162-174.

Gu T-P, Guo F, Yang H, Wu H-P, Xu G-F, Liu W, Xie Z-G, Shi L, He X, Jin S-G, et al. 2011. The role of Tet3 DNA dioxygenase in epigenetic reprogramming by oocytes. Nature 477 : 606-610.

Hajkova P, Jeffries SJ, Lee C, Miller N, Jackson SP, Surani MA. 2010. Genome-wide reprogramming in the mouse germ line entails the base excision repair pathway. Science 329: $78-82$.

Hanna CW, Kelsey G. 2014. The specification of imprints in mammals. Heredity 113: 176-183.

Hirasawa R, Chiba H, Kaneda M, Tajima S, Li E, Jaenisch R, Sasaki H. 2008. Maternal and zygotic Dnmtl are necessary and sufficient for the maintenance of DNA methylation imprints during preimplantation development. Genes Dev 22: $1607-1616$.

Howell CY, Bestor TH, Ding F, Latham KE, Mertineit C, Trasler JM, Chaillet JR. 2001. Genomic imprinting disrupted by a maternal effect mutation in the Dnmt1 gene. Cell 104: $829-838$

Hu G, Kim J, Xu Q, Leng Y, Orkin SH, Elledge SJ. 2009. A genome-wide RNAi screen identifies a new transcriptional module required for self-renewal. Genes Dev 23: 837-848.

Huang C, Martin S, Pfleger C, Du J, Buckner JH, Bluestone JA, Riley JL, Ziegler SF. 2013. Cutting Edge: A novel, humanspecific interacting protein couples FOXP3 to a chromatinremodeling complex that contains KAP1/TRIM28. J Immunol 190: 4470-4473.

Iqbal K, Jin S-G, Pfeifer GP, Szabó PE. 2011. Reprogramming of the paternal genome upon fertilization involves genomewide oxidation of 5-methylcytosine. Proc Natl Acad Sci 108: 3642-3647.

Iyengar S, Farnham PJ. 2011. KAP1 protein: An enigmatic master regulator of the genome. J Biol Chem 286: $26267-$ 26276.

Jacobs FMJ, Greenberg D, Nguyen N, Haeussler M, Ewing AD, Katzman S, Paten B, Salama SR, Haussler D. 2014. An evolutionary arms race between KRAB zinc-finger genes ZNF91/93 and SVA/L1 retrotransposons. Nature 516: $242-$ 245.

Jin VX, O’Geen H, Iyengar S, Green R, Farnham PJ. 2007. Identification of an OCT4 and SRY regulatory module using integrated computational and experimental genomics approaches. Genome Res 17: 807-817.

Kamitani S, Ohbayashi N, Ikeda O, Togi S, Muromoto R, Sekine Y, Ohta K, Ishiyama H, Matsuda T. 2008. KAP1 regulates type I interferon/STAT1-mediated IRF-1 gene expression. Biochem Biophys Res Commun 370: 366-370.

Kamitani S, Togi S, Ikeda O, Nakasuji M, Sakauchi A, Sekine Y, Muromoto R, Oritani K, Matsuda T. 2011. Krüppel-associated box-associated protein 1 negatively regulates TNF- $\alpha$ induced NF- $\mathrm{KB}$ transcriptional activity by influencing the interactions among STAT3, p300, and NF-кB/p65. J Immunol 187: 2476-2483.

Kigami D, Minami N, Takayama H, Imai H. 2003. MuERV-L is one of the earliest transcribed genes in mouse one-cell embryos. Biol Reprod 68: 651-654.

Lander ES, Linton LM, Birren B, Nusbaum C, Zody MC, Baldwin J, Devon K, Dewar K, Doyle M, FitzHugh W, et al. 2001. Initial sequencing and analysis of the human genome. Nature 409: $860-921$.

Li Z, Wang D, Na X, Schoen SR, Messing EM, Wu G. 2003. The VHL protein recruits a novel KRAB-A domain protein to repress HIF-1 $\alpha$ transcriptional activity. EMBO $J$ 22: $1857-1867$.

Li X, Ito M, Zhou F, Youngson N, Zuo X, Leder P, FergusonSmith AC. 2008. A maternal-zygotic effect gene, Zfp57, maintains both maternal and paternal imprints. Dev Cell 15: 547-557.

Liang Q, Deng H, Li X, Wu X, Tang Q, Chang T-H, Peng H, Rauscher FJ, Ozato K, Zhu F. 2011. Tripartite motif-contain- 
ing protein 28 is a small ubiquitin-related modifier E3 ligase and negative regulator of IFN regulatory factor 7. J Immunol 187: 4754-4763.

Liu Y, Toh H, Sasaki H, Zhang X, Cheng X. 2012. An atomic model of Zfp57 recognition of $\mathrm{CpG}$ methylation within a specific DNA sequence. Genes Dev 26: 2374-2379.

Lorthongpanich C, Cheow LF, Balu S, Quake SR, Knowles BB, Burkholder WF, Solter D, Messerschmidt DM. 2013. Singlecell DNA-methylation analysis reveals epigenetic chimerism in preimplantation embryos. Science 341: 1110-1112.

Macfarlan TS, Gifford WD, Driscoll S, Lettieri K, Rowe HM, Bonanomi D, Firth A, Singer O, Trono D, Pfaff SL. 2012. Embryonic stem cell potency fluctuates with endogenous retrovirus activity. Nature 487: 57-63.

Magnúsdóttir E, Surani MA. 2014. How to make a primordial germ cell. Development 141: 245-252.

Maruyama A, Nishikawa K, Kawatani Y, Mimura J, Hosoya T, Harada N, Yamamato M, Itoh K. 2011. The novel Nrf2-interacting factor KAP1 regulates susceptibility to oxidative stress by promoting the Nrf2-mediated cytoprotective response. Biochem J 436: 387-397.

Matsui T, Leung D, Miyashita H, Maksakova IA, Miyachi H, Kimura H, Tachibana M, Lorincz MC, Shinkai Y. 2010. Proviral silencing in embryonic stem cells requires the histone methyltransferase ESET. Nature 464: 927-931.

McGrath J, Solter D. 1984. Completion of mouse embryogenesis requires both the maternal and paternal genomes. Cell 37: $179-183$.

Messerschmidt DM. 2012. Should I stay or should I go: Protection and maintenance of DNA methylation at imprinted genes. Epigenetics 7: 969-975.

Messerschmidt DM, de Vries W, Ito M, Solter D, FergusonSmith A, Knowles BB. 2012. Trim28 is required for epigenetic stability during mouse oocyte to embryo transition. Science 335: 1499-1502.

Messerschmidt DM, Knowles BB, Solter D. 2014. DNA methylation dynamics during epigenetic reprogramming in the germline and preimplantation embryos. Genes Dev 28: $812-828$.

Mouse Genome Sequencing Consortium, Waterston RH, Lindblad-Toh K, Birney E, Rogers J, Abril JF, Agarwal P, Agarwala R, Ainscough R, Alexandersson M, et al. 2002. Initial sequencing and comparative analysis of the mouse genome. Nature 420: 520-562.

Nielsen AL, Ortiz JA, You J, Oulad-Abdelghani M, Khechumian R, Gansmuller A, Chambon P, Losson R. 1999. Interaction with members of the heterochromatin protein 1 (HP1) family and histone deacetylation are differentially involved in transcriptional silencing by members of the TIF1 family. EMBO J 18: 6385-6395.

Nishitsuji H, Abe M, Sawada R, Takaku H. 2012. ZBRK1 represses HIV-1 LTR-mediated transcription. FEBS Lett 586: $3562-3568$.

Nishitsuji H, Sawada L, Sugiyama R, Takaku H. 2015. ZNF10 inhibits HIV-1 LTR activity through interaction with NF-кB and Sp1 binding motifs. FEBS Lett 589: 2019-2025.

Okano M, Bell DW, Haber DA, Li E. 1999. DNA methyltransferases Dnmt3a and Dnmt3b are essential for de novo methylation and mammalian development. Cell 99: 247-257.

Okumura K, Sakaguchi G, Naito K, Tamura T, Igarashi H. 1997. HUB1, a novel Krüppel type zinc finger protein, represses the human $\mathrm{T}$ cell leukemia virus type I long terminal repeat-mediated expression. Nucleic Acids Res 25: 5025-5032.

Peaston AE, Evsikov AV, Graber JH, de Vries WN, Holbrook AE, Solter D, Knowles BB. 2004. Retrotransposons regulate host genes in mouse oocytes and preimplantation embryos. Dev Cell 7: 597-606.

Peng H, Ivanov AV, Oh HJ, Lau YFC, Rauscher FJ. 2009. Epigenetic gene silencing by the SRY protein is mediated by a KRAB-O protein that recruits the KAP1 co-repressor machinery. J Biol Chem 284: 35670-35680.

Peters J. 2014. The role of genomic imprinting in biology and disease: An expanding view. Nat Rev Genet 15: 517-530.
Quenneville S, Verde G, Corsinotti A, Kapopoulou A, Jakobsson J, Offner S, Baglivo I, Pedone PV, Grimaldi G, Riccio A, et al. 2011. In embryonic stem cells, ZFP57/KAP1 recognize a methylated hexanucleotide to affect chromatin and DNA methylation of imprinting control regions. Mol Cell 44: 361-372.

Ratnam S, Mertineit C, Ding F, Howell CY, Clarke HJ, Bestor TH, Chaillet JR, Trasler JM. 2002. Dynamics of Dnmt1 methyltransferase expression and intracellular localization during oogenesis and preimplantation development. Dev Biol 245: 304-314.

Reik W. 2007. Stability and flexibility of epigenetic gene regulation in mammalian development. Nature 447: 425432.

Rowe HM, Jakobsson J, Mesnard D, Rougemont J, Reynard S, Aktas T, Maillard PV, Layard-Liesching H, Verp S, Marquis $\mathrm{J}$, et al. 2010. KAP1 controls endogenous retroviruses in embryonic stem cells. Nature 463: 237-240.

Ryan RF, Schultz DC, Ayyanathan K, Singh PB, Friedman JR, Fredericks WJ, Rauscher FJ. 1999. KAP-1 corepressor protein interacts and colocalizes with heterochromatic and euchromatic HP1 proteins: A potential role for Krüppel-associated box-zinc finger proteins in heterochromatin-mediated gene silencing. Mol Cell Biol 19: 4366-4378.

Santos F, Dean W. 2004. Epigenetic reprogramming during early development in mammals. Reproduction 127: 643-651.

Satou A. 2001. A novel transrepression pathway of c-Myc. Recruitment of a transcriptional corepressor complex to c-Myc by MM-1, a c-Myc-binding protein. J Biol Chem 276: $46562-46567$.

Satou A, Hagio Y, Taira T, Iguchi-Ariga SMM, Ariga H. 2004. Repression of the c-fms gene in fibroblast cells by c-MycMM-1-TIF1 $\beta$ complex. FEBS Lett 572: 211-215.

Schultz DC, Friedman JR, Rauscher FJ. 2001. Targeting histone deacetylase complexes via KRAB-zinc finger proteins: The PHD and bromodomains of KAP-1 form a cooperative unit that recruits a novel isoform of the Mi-2 $\alpha$ subunit of NuRD. Genes Dev 15: 428-443.

Schultz DC, Ayyanathan K, Negorev D, Maul GG, Rauscher FJ. 2002. SETDB1: A novel KAP-1-associated histone H3, lysine 9-specific methyltransferase that contributes to HP1-mediated silencing of euchromatic genes by KRAB zinc-finger proteins. Genes Dev 16: 919-932.

Seisenberger S, Andrews S, Krueger F, Arand J, Walter J, Santos F, Popp C, Thienpont B, Dean W, Reik W. 2012. The dynamics of genome-wide DNA methylation reprogramming in mouse primordial germ cells. Mol Cell 48: 849-862.

Seki Y, Kurisaki A, Watanabe-Susaki K, Nakajima Y, Nakanishi M, Arai Y, Shiota K, Sugino H, Asashima M. 2010. TIF1ß regulates the pluripotency of embryonic stem cells in a phosphorylation-dependent manner. Proc Natl Acad Sci 107: 10926-10931.

Surani MAH, Barton SC, Norris ML. 1984. Development of reconstituted mouse eggs suggests imprinting of the genome during gametogenesis. Nature 308: 548-550.

Takahashi K, Sugi Y, Hosono A, Kaminogawa S. 2009. Epigenetic regulation of TLR4 gene expression in intestinal epithelial cells for the maintenance of intestinal homeostasis. $J$ Immunol 183: 6522-6529.

Tan X, Xu X, Elkenani M, Smorag L, Zechner U, Nolte J, Engel W, Pantakani DVK. 2013. Zfp819, a novel KRAB-zinc finger protein, interacts with KAP1 and functions in genomic integrity maintenance of mouse embryonic stem cells. Stem Cell Res 11: $1045-1059$.

Thomas JH, Schneider S. 2011. Coevolution of retroelements and tandem zinc finger genes. Genome Res 21: 1800-1812.

Tsuruma R, Ohbayashi N, Kamitani S, Ikeda O, Sato N, Muromoto R, Sekine Y, Oritani K, Matsuda T. 2007. Physical and functional interactions between STAT3 and KAP1. Oncogene 27: 3054-3059.

Walsh CP, Chaillet JR, Bestor TH. 1998. Transcription of IAP endogenous retroviruses is constrained by cytosine methylation. Nat Genet 20: 116-117. 
Wang C, Ivanov A, Chen L, Fredericks WJ, Seto E, Rauscher FJ, Chen J. 2005. MDM2 interaction with nuclear corepressor KAP1 contributes to p53 inactivation. EMBO J 24: 32793290.

Wang C, Rauscher FJ, Cress WD, Chen J. 2007. Regulation of E2F1 function by the nuclear corepressor KAP1. J Biol Chem 282: 29902-29909.

Wiznerowicz M, Jakobsson J, Szulc J, Liao S, Quazzola A, Beermann F, Aebischer P, Trono D. 2007. The Krüppel-associated box repressor domain can trigger de novo promoter methylation during mouse early embryogenesis. J Biol Chem 282: $34535-34541$

Wolf D, Goff SP. 2009. Embryonic stem cells use ZFP809 to silence retroviral DNAs. Nature 458: 1201-1204.

Wolf G, Greenberg D, Macfarlan TS. 2015a. Spotting the enemy within: Targeted silencing of foreign DNA in mammalian genomes by the Krüppel-associated box zinc finger protein family. Mobile DNA 6: 17

Wolf G, Yang P, Füchtbauer AC, Füchtbauer E-M, Silva AM, Park C, Wu W, Nielsen AL, Pedersen FS, Macfarlan TS. 2015b. The KRAB zinc finger protein ZFP809 is required to initiate epigenetic silencing of endogenous retroviruses. Genes Dev 29: $538-554$

Wossidlo M, Nakamura T, Lepikhov K, Marques CJ, Zakhartchenko V, Boiani M, Arand J, Nakano T, Reik W, Walter J. 2011. 5 -Hydroxymethylcytosine in the mammalian zygote is linked with epigenetic reprogramming. Nat Commun 2: 241.

Yearim A, Gelfman S, Shayevitch R, Melcer S, Glaich O, Mallm J-P, Nissim-Rafinia M, Cohen A-HS, Rippe K, Meshorer E, et al. 2015. HP1 is involved in regulating the global impact of DNA methylation on alternative splicing. Cell Rep 10: $1122-1134$.

Zheng L, Pan H, Li S, Flesken-Nikitin A, Chen PL, Boyer TG, Lee WH. 2000. Sequence-specific transcriptional corepressor function for BRCA1 through a novel zinc finger protein, ZBRK1. Mol Cell 6: 757-768.

Zuo X, Sheng J, Lau H-T, McDonald CM, Andrade M, Cullen DE, Bell FT, Iacovino M, Kyba M, Xu G, et al. 2012. Zinc finger protein ZFP57 requires its co-factor to recruit DNA methyltransferases and maintains DNA methylation imprint in embryonic stem cells via its transcriptional repression domain. J Biol Chem 287: 2107-2118. 


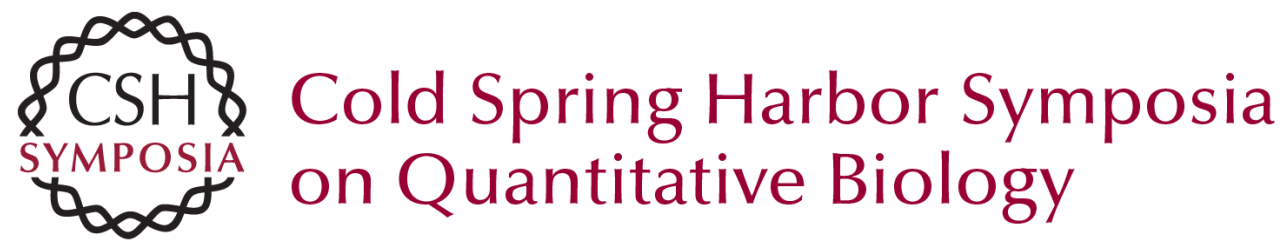

\section{Erase-Maintain-Establish: Natural Reprogramming of the Mammalian Epigenome}

Milena Leseva, Barbara B. Knowles, Daniel M. Messerschmidt, et al.

Cold Spring Harb Symp Quant Biol 2015 80: 155-163 originally published online January 13, 2016

Access the most recent version at doi:10.1101/sqb.2015.80.027441

References This article cites 74 articles, 35 of which can be accessed free at: http://symposium.cshlp.org/content/80/155.full.html\#ref-list-1

\section{License}

Email Alerting Receive free email alerts when new articles cite this article - sign up in Service the box at the top right corner of the article or click here. 